Published in final edited form as:

Policing. 2015 ; 38(3): 458-477. doi:10.1108/PIJPSM-03-2015-0029.

\title{
Characteristics of officer-involved vehicle collisions in California
}

\author{
Scott E. Wolfe \\ Department of Criminology and Criminal Justice, University of South Carolina, Columbia, South \\ Carolina, USA \\ Jeff Rojek \\ Department of Criminal Justice, University of Texas at El Paso, EI Paso, Texas, USA \\ Geoff Alpert \\ Department of Criminology and Criminal Justice, University of South Carolina, Columbia, South \\ Carolina, USA \\ Hope Tiesman \\ Centers for Disease Control, National Institute for Occupational Safety and Health, Morgantown, \\ West Virginia, USA \\ Stephen James \\ Department of Criminology and Criminal Justice, Washington State University, Pullman, \\ Washington, USA
}

\section{Abstract}

Purpose-The purpose of this paper is to examine the situational and individual officer characteristics of officer-involved vehicle collisions that result in fatality, injury, and non-injury outcomes.

Dr Scott E. Wolfe is the corresponding author and can be contacted at: swolfe@mailbox.sc.edu.

About the authors

Dr Scott E. Wolfe is an Assistant Professor in the Department of Criminology and Criminal Justice at the University of South

Carolina. He received his PhD from the Arizona State University in 2012. His research has appeared in a variety of scholarly journals, including the British Journal of Criminology, Criminal Justice and Behavior, and Crime \& Delinquency.

Dr Jeff Rojek is an Associate Professor in the Department of Criminal Justice at the University of Texas at El Paso. His research primary focusses on law enforcement organizations and officer behavior, and has appeared in Policing: An International Journal of Police Strategies \& Management, Police Quarterly, Criminology, Justice Quarterly, and Journal of Research in Crime and Delinquency.

Geoff Alpert is a Professor in the Department of Criminology and Criminal Justice at the University of South Carolina. Professor Alpert has been conducting research on high-risk police activities for more than 30 years, and has published results from his research in the academic and professional literature. His most recent grant is evidence-based solutions to reduce law enforcement officer vehicular crashes funded by the Bureau of Justice Assistance.

Dr Hope Tiesman is a Research Epidemiologist with the National Institute for Occupational Safety and Health (NIOSH). Dr Tiesman completed her MSPH in epidemiology from the University of South Florida and her PhD in epidemiology from the University of Iowa. While at Iowa, she was a Fellow in the occupational injury prevention research program at the Heartland Center for Occupational Health \& Safety. She has an Adjunct Academic Appointment in the West Virginia University (WVU) College of Public Health and is Affiliate Faculty at the WVU Injury Control Research Center. At NIOSH, her research focusses on motor-vehicle crashes among law enforcement officers, workplace suicide, and workplace violence prevention.

Stephen James is a Doctoral Candidate in the Department of Criminal Justice and Criminology at the Washington State University. He has managed the Simulated Hazardous Operational Tasks Laboratory at the Sleep and Performance Center, Washington State University, Spokane. James has been a Member of the CA POST Safe Driving Research Team since 2009. 
Design/methodology/approach-Data on 35,840 vehicle collisions involving law enforcement officers in California occurring between January 2000 and December 2009 are examined. A descriptive analysis of collision characteristics is presented.

Findings-There were 39 officers killed by collisions over this study period and 7,684 officers who received some type injury. Incidents involving officers on motorcycles represented 39 percent of officer fatalities and 39 percent of severe injuries. In the case of fatalities, 33 percent of officers were reported as wearing seatbelts, 38 percent were not wearing a seatbelt, and seatbelt use was not stated in 29 percent of car fatalities.

Research limitations/implications-The findings only represent one state and the analysis is based on an estimated 86 percent of collisions that occurred during the study period due to missing data. Nonetheless, the results are based on a robust sample and address key limitations in the existing literature.

Practical implications-During the study period in California the estimated financial impact of collisions reached into the hundreds of millions of dollars when considering related fatality, injury, and vehicle damage costs combined. These impacts highlight the need for the law enforcement community to give greater attention to this issue.

Originality/value-At the time of this writing there was no published independent research that compares the situational and officer characteristics across fatality, injury, and non-injury outcomes in these events. The findings reported here will help inform emerging interest in this issue within the law enforcement, academic, and policy-making communities.

\section{Keywords}

Law enforcement; Crashes; Officer; Vehicle collisions

Following the unfortunate rise in the number of law enforcement officers killed in the USA between 2010 and 2011, the Bureau of Justice Assistance and Office of Community Oriented Policing Services created the national Officer Safety and Wellness (OSW) group to identify and support efforts to improve officer safety (Stephens et al., 2012). One of the more notable observations from the OSW group was that little is known about officerinvolved vehicle collisions despite these events often being the leading cause of officer fatalities in the USA on an annual basis (Stephens et al., 2013) [ $\left.{ }^{1}\right]$. This issue has largely been ignored by the research community and, as a result, there is virtually no empirical knowledge concerning the prevalence of vehicle collisions, the injury, and fatality outcomes of these events, the characteristics of these collisions, or the characteristics of individuals involved in such incidents. The impact of this empirical gap is a lack of knowledge for developing policy, practice, and training aimed at reducing injuries and fatalities resulting from vehicle collisions. The present study partially addresses this gap in the literature by examining more than 35,000 vehicle collisions involving officers in the State of California between 2000 and 2009. The analysis examines the outcomes of these events and the characteristics of the collisions and offices involved.

${ }^{1}$ This finding is observed when comparing gunshot fatalities to automobile and motorcycle fatalities (see National Law Enforcement Officers Memorial Fund, www.nleomf.org/facts/officer-fatalities-data/causes.html). 


\section{Officer-involved vehicle collisions}

The deaths of officers due to vehicle collisions have immeasurable emotional costs for these officers' families, friends, and departments. In addition, non-fatal injury collisions also carry significant burdens to involved officers who may suffer significant physical or psychological trauma, some of which lead to long-term disabilities and expensive therapies. At an even broader level, officer-involved collisions may also cause injury or death to citizens.

There are also significant financial costs associated with officer-involved collisions. For each officer killed in the line of duty the federal government (through the Public Safety Officers' Benefits Program) pays the survivors or beneficiaries a minimum of $\$ 333,605$ (Bureau of Justice Assistance, n.d.). In addition, a report by the National Highway Traffic Safety Administration (NHTSA) estimated that the average fatal vehicle collision had an approximate total cost of \$1.4 million (Blincoe et al., 2014). This estimate includes such costs as medical care, lost market productivity, legal expenses, emergency service, and property damage. NHTSA estimated that, on average, 9 percent of these costs would be paid by federal and state governments for collisions that resulted in citizen death. In the case of law enforcement officers, however, these costs are going to be almost entirely carried by federal, state, and local governments. Given that the annual number of officers killed from automobile and motorcycle collisions across the USA has ranged from 48 to 60 over the past ten years (Federal Bureau of Investigations (FBI), 2008), the total cost to federal, state, and local governments resulting from these incidents is in the tens of millions of dollars annually. Importantly, however, this figure does not consider the more numerous non-fatal injury collisions $\left[{ }^{2}\right]$. According to NHTSA such incidents resulted in costs that range from roughly $\$ 13,300$ to $\$ 1,100,000$ per collision in 2010 (approximately $\$ 37,000$ to $\$ 5.5$ million with inclusion of loss of quality of life costs) depending on the classification of injury severity (Blincoe et al., 2014).

Paradoxically, the seriousness of law enforcement collisions is counterbalanced by perceptions among officers that driving is an innocuous event (Dorn and Brown, 2003). In other words, the routine and normality of driving is often viewed as merely part of an officer's employment, reinforcing the idea that vehicle collisions are inevitably going to occur and are unavoidable. This sentiment fails to appreciate that the occupational responsibility of officers requires them to engage in driving actions that place them at higher risk for collisions than the average citizen driver. Officers spend considerably more time in a vehicle than an average citizen. Moreover, officers engage in atypical driving actions such as vehicle pursuits and responding to emergency calls at high speeds that may involve the legal violation of roadway laws. Officers must also routinely conduct traffic stops and engage in traffic management alongside moving vehicles. Rix et al. (1997) note that the collision exposure of officers is even unique from other emergency occupations such as fire and ambulance. While the latter may also travel at high speeds and legally violate roadway rules in response to emergency calls, they do not engage in routine patrol like officers that results in further collision risk exposure.

\footnotetext{
${ }^{2}$ The CalPOST estimates there are 100 officer injury collisions for each officer fatal collision in California annually (Gustafson and Cappitelli, 2010).
} 
Unfortunately, the failure of officers and police leadership to recognize their higher risk exposure only serves to reinforce unsafe practices, underestimates the impact that evidencebased research can provide, and delivers no guidance to key stakeholders on how to improve driving safety. The development of evidence-based efforts to improve officer safety in this area has also been limited by a lack of comprehensive research conducted on the topic. In the area of officer safety, the academic community has almost exclusively focussed on police pursuits and the subsequent collisions that may occur (Alpert, 1987, 1997; Alpert and Dunham, 1989; Crew et al., 1994; Payne and Fenske, 1996; Crew and Hart, 1999). While this line of research has been informative and provides insight into reducing such collisions, it captures only a small portion of vehicle collisions among law enforcement. For example, Alpert and Dunham (1989) found that only 5 percent of police vehicle collisions were related to pursuits. As a result, the narrow pursuit collision focus limits our knowledge on strategies for reducing overall officer-involved collision rates.

Despite lack of research attention from the academic community, there have been a handful of government agencies in the UK and USA that have investigated the issue. A British Home Office study published in 1997 that examined officer-involved collisions resulting in serious injuries or fatalities represented the first of these efforts (Rix et al., 1997). The study examined the prevalence and trend in officer-involved collisions in England and Wales from 1991 to 1995 based on official reports from all 42 police forces, which was supplemented by an analysis that examined a sample of the collisions to capture incident characteristics. The first of such research in the USA was conducted by California Commission of Peace Officer Standards and Training (CalPOST) (2009). The primary focus of the California Commission of Peace Officer Standards and Training (CalPOST) report was to examine the impact of different forms of driver training on collisions. In the process, however, the report also provided preliminary analysis regarding characteristics of officers involved in fatal and injury collisions in California and related situational factors. Building on these efforts, a recent study by NHTSA provides the most detailed analysis of officer-involved collisions to date (Noh, 2011). The study is based on data from the Fatality Analysis Reporting Systems (FARS) maintained by NHTSA and examined the situational and officer characteristics of vehicle collision events that resulted in the death of 823 police officers in the USA between 1980 and 2008.

Collectively, the Home Office, CalPOST, and NHTSA reports have provided insight into the limited literature concerning officer-involved collisions. The problem, however, is that a holistic examination of officer-involved collisions that captures fatality, injury, and noninjury outcomes in absent from the literature to date. This gap limits our understanding of the prevalence of these outcomes relative to one another and within specific degree of injury categories. Moreover, little is known about the differences in situational and officer characteristics across these outcomes. The present study addresses these limitations through the analysis of a large data set of officer-involved collisions in California. The resulting analysis provides a foundation for a more in-depth understand of these events and a strong basis for identifying future research and policy objectives. 


\section{Data and methods}

The data for the present analysis come from a larger study on officer-involved collisions funded by the National Institute of Justice (NIJ). The data set is the product of merging data from the Statewide Integrated Traffic Records System (SWITRS) database maintained by the California Highway Patrol (CHP), collision records from the California Department of Motor Vehicles (DMV), and CalPOST records on commissioned law enforcement officers in California. The analysis captures 35,840 vehicle collision events between 2000 and 2009 where at least one involved driver was a law enforcement officer.

\section{Data}

As noted above, the SWITRS data used in this study are collected and maintained by CHP. The database is the product of local and state law enforcement officers completing the CHP 555 traffic collision reporting form, which is the universal traffic collision documentation for all California law enforcement. The 555 form is a comprehensive traffic investigation report that captures information on the parties involved, behaviors of the parties (e.g. driving violations), environmental conditions at the time of event, and degree of injury outcomes. The recording of this information is largely accomplished through fill-in-the-blank boxes on the form and coded responses that are informed by the California Highway Patrol (2003) Collision Investigation Manual. Additional information is captured through a narrative description of the incident and diagrams. The SWITRS data excludes direct identifiable information such as name, address, driver's license number, or vehicle license plate numbers for involved parties.

Per California Vehicle Code 20008, law enforcement agencies are required to investigate all reported traffic collisions involving a fatality or injury and forward the completed investigative report to CHP. The submission of reports involving only property damage is not required under this code, but it is encouraged for the purpose of developing better knowledge of traffic collisions (CHP, 2003). The difference in required and encouraged reporting procedures posed potential issues in capturing the fatality, injury, and non-injury collisions of interest to the present study and the larger NIJ project. Several of the authors of the current study have worked with California law enforcement agencies for the past four years concerning officer-involved traffic collisions. As a result, we have learned from law enforcement officials that agencies will typically complete 555 reports for non-injury collisions for the purpose of internal administrative review and documentation purposes in anticipation of potential liability claims by individuals involved in the collisions (e.g. citizens). However, there is no ability to verify this information based on the SWITRS data alone.

A second potential issue with the SWITRS data are the identification of law enforcement vehicles based on coding practices on the 555 form. Two codes are used on the form to identify the type of law enforcement vehicle - one identifying police cars and the other police motorcycles $\left[{ }^{3}\right]$. However, California law enforcement officials informed the authors that an older version of the 555 form had the term "CHP USE ONLY" directly over the area

\footnotetext{
${ }^{3}$ This includes the identification of police vehicles regardless of whether they are in emergency service.
} 
where this vehicle type coding was entered. Local law enforcement officers properly trained to complete the 555 form knew to still enter the vehicle type coding in this box, but for several years a significant number of forms did not include a vehicle code due to the confusing juxtaposition of the term. Later versions of this form have removed the term over the vehicle code box. It was unknown at the outset of the larger NIJ project the extent to which local officers were failed to complete the vehicle type coding and, thereby, not properly identifying law enforcement vehicles that should be included in the current study.

To assess the issues of complete reporting of all law enforcement collisions and proper coding of police vehicles involved, we drew on collision data collected by the California DMV. All officers in the State of California are certified by CalPOST. As a result, CalPOST keeps a registry of all certified officers, along with background information on officer demographics, start, and departure dates with agencies, and key to the present study, the driver's license number of each officer. The license numbers were forwarded to the California DMV with a request for data on all collisions reported in relation to these numbers (i.e. cases where the officers were drivers in reported collisions).

California DMV collects information on vehicle collisions through form SR1, which captures information on the drivers involved, date, time, and location of the incident, insurance verification, and identification of whether the collision involved an injury or fatality. In accordance with California Vehicle Code 16004, collisions involving a fatality, injury, or damage more than $\$ 750$ in value, regardless of fault or if on private property, must be reported on the SR1 form to the DMV within ten days of the collision. This reporting requirement includes law enforcement officers involved in collisions while in the performance of their job.

The data provided by the California DMV, however, contained the SR1 information for all collisions attached to the license numbers we requested. This resulted in the inclusion of officers involved in collisions that occurred in police vehicles and those that occurred in private vehicles while off duty. To remedy this issue, information was examined within the DMV data pertaining to whether the vehicle driven by the officer was an emergency vehicle and/or had exempt plates. This provided us the ability to retain cases that were law enforcement vehicles and eliminate those that involved an officer who was driving a personal vehicle during the time of the collision (i.e. those cases with non-exempt plates). The overall information provided in the DMV SR1 form is rather limited and does not offer the wealth of data found in the SWITRS database. However, the DMV does provide the complete pool of reported collisions involving law enforcement personnel with a fatality, injury, or damage of consequence (i.e. damage of $\$ 750$ or more in value) whereas the SWITRS data only include collisions that resulted in injury or fatality. In short, the current study needed both the DMV and SWITRS databases to provide a holistic analysis of officerinvolved collisions.

Accordingly, the DMV and SWITRS data were merged to evaluate whether agencies were reporting to SWITRS all collisions of consequence (fatalities, injuries, and notable damage). This merge also provided the ability to identify law enforcement collisions that were not properly coded in SWITRS as a police vehicle as discussed above. It is important to note 
there was no common unique case identifier present in both data sets that would allow for a simple merge process. As a result, the authors developed a process of creating variables that would allow cases in each database to align and be merged. The process of such linking efforts is common practice in public health research (Whalen et al., 2001).

Overall, this merge process lead to 35,840 cases in the SWITRS files being matched to a DMV case over the observation period (i.e. 2000 through 2009), representing an 86 percent overall match rate for the ten-year period (the annual match rate varies between 81 and 95 percent across the years). The 14 percent non-match rate is a limitation but there is no evidence this missing data are not random or creates bias in the analysis. In short, we are confident in the validity of our results given the nearly 36,000 officer-involved collisions over the observation period are included in our analysis. Further, the authors reviewed the California Peace Officers' Memorial Foundation and Officer Down Memorial web sites and were able to verify that all officer collision fatalities were included in the merged data set.

A few additional limitations or boundaries to the data set deserve acknowledgment. First, the data only include events where at least one party was the driver of a vehicle (i.e. car or motorcycle). Cases where officers were a pedestrian (i.e. on foot or bicycle) are not included because the DMV-based records require a driver for reporting. Second, there is no ability to determine if the driving officer was on or off duty during the time of the collision. This is an issue for cases where officers have take-home vehicles. The CHP manual for the 555 form notes that the investigating officer is to identify if the police vehicle is on duty, but this is a hand written notation next to the drivers name and is not recorded in the SWITRS data. According to the 2007 Law Enforcement Management and Administrative Statistics Survey, 50 percent of law enforcement agencies in the USA allow law enforcement vehicles to be driven home by officers (Reaves, 2010). In many cases, however, this is only allowed for select administrative and investigative personnel. The actual percentage of agencies that allow all patrol, investigative, and other personnel to drive their vehicles home is likely much lower. Perhaps most importantly, examining both on- and off-duty officers involved in collisions while driving a law enforcement vehicle is relevant for the current analysis because the agency in either case is responsible for damage to the vehicle, harm to the officer, and liability claims from other parties involved. Third, the data set only contains information on officers working for municipal police departments, county sheriff/police departments, and CHP which are the vast majority of agencies in California. Other special agencies (e.g. university police, wildlife wardens) are not included in our analysis.

\section{Analytic strategy}

The present study will use the combined DMV and SWITRS database to provide a descriptive analysis aimed at addressing several gaps in the literature. For starters, we will examine the prevalence of officer-involved collisions and the injuries and fatalities that resulted from such incidents in California over the observation period (2000-2009). Next, the demographic characteristics of officers involved in collisions will be examined. We also explore the distribution of collisions across agency size. We then turn to an analysis of the basic characteristics of officer-involved collisions to understand the distribution of these 
events across months of the year, days of the week, times of the day, road conditions, locations, collision types, alcohol involvement, and single- vs multiple-vehicle collisions.

Given the importance of injuries sustained to officers involved in such collisions, the second part of the analysis determines whether officer demographic characteristics are associated with being injured or killed. More importantly, we also examine the distribution of officer injury severity by the type of vehicle that was being driven during the collision. We conclude the analysis with a look at whether officer seatbelt use is associated with degree of injury severity. Overall, this analysis provides a more comprehensive examination of law enforcement vehicle collisions than the FARS study discussed earlier (Noh, 2011) by simultaneously exploring fatal, injury, and non-injury outcome collisions.

\section{Results}

\section{Frequency of officer-involved collisions, injuries, and fatalities}

Table I examines the frequency of officer-involved collisions, injuries, and fatalities throughout the ten-year observation period. The first column reveals that 35,840 officerinvolved collisions occurred in California from 2000 to 2009. Recall that this represents collisions that occurred with officers employed at a municipal police department, county sheriff/police department, or CHP, and resulted in damage of $\$ 750$ or more, injury, or fatality. Accordingly, an average of about 3,600 officer-involved collisions occurred each year in California. While these data are only from a single state, they provide some of the first insight regarding the prevalence of officer-involved collisions that include non-injury (with damage of consequence), injury, and fatal outcomes (CalPOST, 2009; Noh, 2011; Rix et al., 1997).

Among these collisions, 7,684 officers were injured to some degree. It is important to note that these values are derived from the officer level of analysis. As such, multiple officer drivers could be involved in single collision and result in multiple officer injuries. The fifth column in Table I calculates the percentage of all collisions that resulted in an injury. These values were calculated by dividing the number of collisions that had at least one officer injured by the total number of officer-involved collisions during each year. On average, 21.2 percent of collisions caused some type of injury to the involved officers $\left[{ }^{4}\right]$. Finally, Table I reveals that a total of 39 officers were killed in traffic collisions during the ten-year period. Between three and seven officers die every year in California as a result of these collisions (average $=3.9$ fatalities).

\section{Characteristics of officers involved in traffic collisions}

Table II explores the demographic characteristics of officers involved in traffic collisions. Consistent previous research, a vast majority of collisions involved male officers (91.1 percent; see, Noh, 2011). Less than 9 percent of collisions involved a female officer driver. About two-thirds of collisions involved a white officer driver (65.6 percent). In more than

\footnotetext{
${ }^{4}$ Due to fluctuations in the SWITRS and DMV match rates across the observation years, we believe it would be irresponsible to discuss whether changes in the trends reported in Table I are statistically significant. After all, we would have no ability to determine what factors were associated with any change (e.g. reporting practice changes).
} 
one-fifth of these events, however, a Hispanic officer was the driver during the collision (22.0 percent). Collisions were much less likely to involve drivers who were black (6.2 percent), Asian (4.2 percent), or from another racial/ethnic category (1.8 percent). The examination of officer age is interesting given that conventional wisdom among law enforcement officers and administrators is that younger officers are responsible for most traffic collisions (see, CalPOST, 2009). Counter to this belief, these data reveal that the majority of collisions involved officers between the ages of 30 and 39 (44.7 percent). While not trivial, only 24.5 percent of officers involved in such collisions are in the youngest age group (20-29) in our data. Of course, these figures do not speak to collision rates which we discuss later.

\section{Agency size and officer-involved collisions}

Table III explores whether agency size is associated with traffic collision prevalence. The categories were constructed using CalPOST data on the number of full-time sworn (FTS) personnel in each law enforcement agency in California. First, we calculated the ten-year (2000-2009) average FTS for all agencies represented in our analysis. Next, we recoded these values into the following categories: 0-25, 26-50, 51-100, 101-500, 501-999, and 1,000 or more officers. Finally, we merged this agency size variable into our analysis files. The first two columns present the proportion of law enforcement officers in California that are employed by each type of agency (column 1) and the percentage of agencies in the state that fall into each size category (column 2). As expected, small agencies are more common in the state but large agencies employee a much greater proportion of all officers.

The final three columns in Table III examine collision, injury, and fatality prevalence across the various agency sizes. The prevalence of collisions and the percentage of collisions that result in an officer injury or fatality are positively associated with the total number of law enforcement officers employed in each agency group. This is not surprising - more officers translate into greater collision risk and numbers of officers that are injured or killed. Small differences in this trend emerge, but such findings should be interpreted with caution. For example, while agencies with more than 1,000 officers employee 54.1 percent of all officers, they account for a slightly smaller proportion of collisions (52.1 percent). This may be explained by the fact that larger agencies are more compact in terms of population density and average distance required for emergency calls. Nevertheless, a larger portion of officer deaths occur in large agencies (58.8 percent) than may be expected when simply examining the proportion of officers such agencies employ. Finer grained analysis and additional data sources are necessary to explore these relationships in more detail.

\section{Basic characteristics of officer-involved collisions}

The first panel in Table IV examines the distribution of officer-involved collisions over the observation period across each month. With only slight variations, there tended to be an equal number of collisions each month. Specifically, the prevalence of collisions hovered around 3,000 (about 8 percent of all collisions during the observation period) per month (pooled across years). The same pattern of results emerged regarding collision distribution across days of the week. Typically, individual days accounted for about 13-15 percent of all collisions that occurred during the observation period. However, a slightly higher number of 
collisions occurred on Fridays (16.1 percent of all collisions) and a slightly lower proportion on Sundays (11.5 percent). This result would be expected given that Fridays typically experience greater traffic volume. Conversely, roadways tend to be less crowded on Sundays. It is also possible that police agencies have fewer officers on duty during Sundays which would reduce collision risk.

With respect to time of day (see third panel in Table IV), the fewest number of officerinvolved collisions occurred between 00:01 and 06:00 (i.e. 12:01-6:00 a.m.) (14.0 percent). This finding is not surprising given that this timeframe experiences the lightest road traffic. Nearly 23 percent of collisions occur during 06:01 and 12:00. It is somewhat surprising that a higher portion of collisions would not occur during this period which includes morning rush hour. However, this may be due to variation in law enforcement officer coverage (e.g. shift changes). Over one-quarter of all collisions involving officers occurred between 18:01 and 24:00 (midnight). The higher proportion relative to the other time periods may be partially explained by a slightly higher traffic volume during this time that includes the end of evening rush hour and a period where people are off work enjoying their evening routine activities. Finally, the largest number of collisions took place between the hours of 12:01 (noon) and 18:00 (6:00 p.m.). This may be the result of evening rush hour significantly increasing the risk of traffic collisions for law enforcement officers. It is also a period of heavy officer deployment with evening shifts typically starting in the late afternoon. Further research is required to uncover the nuances of the distribution of officer-involved collisions across different times of the day.

\section{Weather and road conditions of officer-involved collisions}

Table $\mathrm{V}$ provides an examination of the number of officer-involved collisions that were categorized as occurring under certain weather, road surface, and lighting conditions. Given the relatively pleasant weather experienced across the most heavily populated regions of California, it is not surprising that a vast majority of collisions were classified as occurring during either clear (80.7 percent) or cloudy (14.4 percent) conditions. In fact, only 3.4 percent of collisions occurred while it was raining. The relatively low occurrence of officerinvolved collisions during rainy conditions may be explained partially by the fact that law enforcement officers have much more training on how to handle such road conditions compared to the average citizen. However, this is purely speculation and more research is required to fully understand this relationship (e.g. California may not receive nearly as much rain as other states). Relatedly, most of these events occurred under dry road conditions (89.3 percent) with only around 8 percent of collisions classified as occurring under wet conditions. Finally, and as expected, most collisions occurred during daylight (59 percent). Still, about 37 percent of officer-involved collisions occurred when it was dark. While our data cannot provide insight regarding collision rates, this finding is interesting because traffic during the night is much lighter than during the day. Thus, our data seem to suggest that darkness may be an important contributing factor to these events. At the same time, other factors that are more likely during night may have an influence on this relationship (e.g. DUI, other criminal activity requiring police response). 


\section{Factors surrounding officer-involved collisions}

Table VI provides descriptive information pertaining to the location of the collisions, types of collisions, and number of vehicles involved in the events. For starters, a majority of officer-involved collisions occurred in "non-intersections" (74.9 percent). About one out of every four collisions occurred in an intersection (24.2 percent). Regarding the types of collisions that occurred, rear end collisions are the most common (30.4 percent), followed by broadsides (22.5 percent), and sideswipes (19.1 percent). A sizeable portion of these events - 16.3 percent - involved an officer hitting an object (e.g. animal, telephone pole, or other fixed object). Lastly, more than three-quarters of collisions involved multiple vehicles (76.5 percent). It is important to note that such events could include an officer colliding with either another officer vehicle or citizen (in a vehicle, bicycle, or as pedestrian). Nearly 24 percent of officer-involved collisions were single-vehicle events.

Additionally, Table VI presents information regarding whether officers involved in the collisions were driving under the influence of alcohol during the time of the collision. Fortunately and as expected, nearly all officers involved in these incidents had not been drinking prior to the collision (98.0 percent). However, 29 officer drivers were found to be under the influence of alcohol at the time of the collision and another 33 had been drinking but were classified as "not under influence." It is important to keep in mind that the data potentially captures off-duty officers in take-home vehicles, which may account for a portion of these cases. Nonetheless, agencies likely have policies regarding drinking while driving department vehicles (on or off duty), let alone the illegality of DUI in either circumstance. The final panel in Table VI provides a breakdown of single- and multiplevehicle collisions by whether the involved officer was found to be "at-fault" for the collision. For single-vehicle collisions, three-quarters of officer drivers were found to be atfault for the incident (75.6 percent). In contrast, only 37.2 percent of officers involved in multiple-vehicle collisions were found to be at-fault. Thus, when another vehicle is involved in the collision, officers are found not to be at-fault nearly 63 percent of the time.

\section{Officer characteristics of injury and fatal collisions}

Table VII takes a closer look at collisions that resulted in injury or death to an officer. The first set of analyses cross-tabulates whether the officer driver was injured or killed with the age categories. The results demonstrate that the group most likely to be injured (45.4 percent) or killed (48.7 percent) are between the ages of 30 and 39. However, this does not take into consideration relative risk. The prevalence ratio is actually highest for the 40-49 age group for injury status $(1.063, p<0.01)$. Thus, 40-49-year olds are about 6 percent more likely to be injured in a collision compared to all other groups. Conversely, the 20-29 age group had the lowest prevalence ratio $(0.898, p<0.01)$ indicating that such officers are about 10 percent less likely to be injured in collisions compared to their counterparts. With respect to fatalities, the only statistically significant prevalence ratio was for the 20-29 age group $(0.353, p<0.05)$. Officers in this age range were about 65 percent less likely to die in a collision compared to all other age groups. This is an interesting effect that calls for additional research (are younger officers more inclined to wear their seatbelt compared to older officers resulting in lower fatality rates for the age group?) 
Consistent with distribution of all collisions by gender, males are represented most commonly across the categories in Table VII. Importantly, however, one exception was observed. All 39 officers killed in a traffic collision between 2000 and 2009 were male. Although the expected number of females was injured in collisions ( 9.1 percent), none died in such incidents.

The final group of cross-tabulations in Table VII separates injury and fatality status by the type of vehicle the officer was driving (i.e. car vs motorcycle) and several important findings emerge. Not surprisingly, most collisions that result in the officer being injured involved incidents were the officer was operating a passenger car ( 82.8 percent). However, over 17 percent of injury collisions involved an officer on a motorcycle. In total, 6 percent of officers involved in traffic collisions were driving a motorcycle. This demonstrates that motorcycles involved in collisions disproportionately account for officer injuries. This is not necessarily surprising given the lack of protection on a motorcycle. Upon closer inspection, however, about 18 percent of officers are injured when they are in a car whereas over 60 percent of officers on a motorcycle are injured when involved in a collision. Indeed, the statistically significant prevalence ratio $(3.251, p<0.01)$ indicates that officers on motorcycles are 225 percent more likely to be injured compared to those involved in car collisions.

Even more striking is the relationship between vehicle type and whether the involved officer was killed during the collision. Of the 39 deaths that resulted from traffic collisions, 15 were officers on motorcycles (38.5 percent). Again, there are logical explanations for the greater likelihood of death on a motorcycle (i.e. less protection than a car) but the chance of an officer dying on this mode of transportation is six times greater than the total number of motorcycles involved in collisions (i.e. 38.5/6 percent). Furthermore, officers are nearly ten times more likely to die in a traffic collision if they are driving a motorcycle compared to a car $($ prevalence ratio $=9.786, p<0.01)$.

\section{Injury severity by officer vehicle type}

Table VIII explores the degree of injury severity based on whether the officer was driving a car or motorcycle. Again, we see that it is far more dangerous for an officer to be on a motorcycle than in a car. For example, 39.2 percent of officers involved in collisions who received a "severe injury" were operating a motorcycle. Further, 27.9 percent of officers who experienced a less severe, yet "visible injury" were on a motorcycle. In contrast, officers were significantly more likely to only "complain of pain" if they were in a car (92.0 percent). Officers on motorcycles were three times more likely than those in cars to have a serious injury or die compared to less severe injuries (prevalence ratio $=3.342, p<0.01$ ). In sum, Tables VII and VIII reveal that officers on motorcycles are disproportionately exposed to injury and death stemming from traffic collisions.

\section{Seatbelt use and officer injury severity}

The final set of analyses attempt to uncover whether the use of a seatbelt during a collision is associated with the degree of injury sustained by involved officers. Tiesman and Heick (2014) found a high level of self-reported seatbelt use while on duty among a sample of 
Iowa officers. However, the authors of the present study have conducted interviews with law enforcement personnel who indicate that non-use of seatbelts is frequent and cite reasons ranging from comfort to the need to quickly exit the vehicle to pursue a suspect or escape an ambush (also see Wehr et al., 2012; Tiesman and Heick, 2014). At the same time, the consequence of not wearing a seatbelt given the high prevalence of officer-involved collisions is potentially significant. Table IX presents findings from a cross-tabulation of officer collisions that resulted in some type of injury by whether a seatbelt was worn during the collision (of course, this analysis only includes officers that were driving a car). First, the data reveal that in 10 percent of injury/fatality collisions the officer driver was not wearing a seatbelt. Indeed, this is a nontrivial number of collisions. Importantly, however, for 15 percent of injury/fatality collisions the CHP 555 form did not state whether or not a seatbelt was worn by the officer during the collision. In many of these cases the 555 form typically listed "unknown" or "air bag deployed" in the field for indicating the type of safety equipment used during the collision. Accordingly, for 1,182 collisions during the observation period that resulted in some form of injury to an officer we have no way to determine whether that officer was wearing a seatbelt.

Simply complaining of pain was the most significant injury sustained in 80 percent of incidents where an officer was wearing a seatbelt at the time of the collision. Only 8.3 percent of collisions where the officer complained of pain involved a driver that was not wearing a seatbelt. The risk of injury or death increased for those who were not wearing a seatbelt restraint. Specifically, 14.2 percent of officers who experienced a visible injury and 18.4 percent of officers who sustained a severe injury were not wearing a seatbelt during the collision. Most importantly, 37.5 percent of officers who died in a collision were not wearing a seatbelt. With respect to relative risk, officers who were not wearing a seatbelt were 180 percent more likely to be seriously injured or killed compared to their counterparts (prevalence ratio $=2.806, p<0.01$ ). Curiously, an examination of the 555 form data revealed that seatbelt use or non-use was not stated in nearly 30 percent of incidents that resulted in an officer death. The implications of these findings are discussed below.

\section{Discussion}

Officer safety is a primary concern of law enforcement agencies. However, an important source of officer injuries and deaths - vehicle collisions - is often neglected by agency executives, policy makers, and researchers. The number of law enforcement officers who die in vehicle collisions is comparable to the numbers that die from felonious killings (e.g. gunshot) on an annual basis (FBI, 2008). What is more, officers are routinely injured in collisions at a far greater rate than those that are killed. The emotional, health related, and financial impact of officer-involved collisions further underscores the consequences of such incidents. In short, serious research attention to this issue is long overdue. The present study's purpose was to begin filling this void in the literature. Based on an analysis of ten years of officer-involved collision data from California, several findings warrant further discussion.

For starters, the analysis demonstrated that vehicle collisions are a significant threat to officer safety. In California from 2000 to 2009, 39 law enforcement officers were killed in a 
traffic collision. The emotional costs of such incidents are incalculable and certainly impact the officers' families, colleagues, and communities they served. There are also financial costs borne as a result of fatal officer collisions. As discussed earlier, NHTSA estimates that the average citizen fatal vehicle collision costs more than $\$ 1.4$ million in medical and legal expenses, lost work productivity, and property damage, and upwards of $\$ 9$ million with the inclusion of loss of quality of life costs (Blincoe et al., 2014). If such an estimate extends to officer collisions, this suggests that the state of California and the counties and municipalities within it collectively lost more than $\$ 54$ million dollars as a result of such incidents. With the inclusion of the costs associated with quality of life losses, the total fatal collision cost could reach $\$ 351$ million. Of course, these estimates must be taken with caution but, nonetheless, demonstrate the potential financial impact of fatal officer-involved collisions. What is more, the present analysis did not examine citizen deaths resulting from officer-involved collisions. As such, the financial impact of these incidents is likely much greater.

While an officer dying in a vehicle collision is the most serious outcome, officers are much more likely to receive a non-fatal injury during these incidents. Our data reveal that 7,684 officers were injured in collisions during the ten-year observation period in California. Thus, contrary to previous estimates (Gustafson and Cappitelli, 2010) our analysis shows that there are about 197 officers injured in vehicle collisions for every one officer killed. These injuries range in severity from an officer simply complaining of pain to serious injuries such as broken limbs. More than 30 percent of collisions that resulted in some form of injury were more severe than complaints of pain. Furthermore, 21 percent of all collisions resulted in some type of injury to an officer. These results clearly demonstrate that officer-involved traffic collisions can involve much more serious incidents than fender-benders in parking lots. Depending on the severity of such injuries, officers may face significant time off of work, long and painful rehabilitation, or life-long disabilities. The financial impact of collisions that result in officer injuries cannot be ignored either. As discussed earlier, NHTSA estimates that the cost of non-fatal injury collisions among the general public typically ranges between $\$ 2,000$ and $\$ 1.1$ million per incident. As such, officer injury collisions likely result in significant financial costs for local and state jurisdictions and, ultimately, the tax payers who fund their budgets.

Future research is clearly needed that can provide a clearer picture regarding the precise financial costs associated with officer-involved collisions. Such analyses will want to take into consideration those collisions that result in fatal and non-fatal injuries to officers and citizens alike. However, it is also important to take into consideration the large portion of collisions without injury given the significant amount of cost associated with property damage. Recall, to be included in the current analyses a collision had to involve an injury, fatality, or at least $\$ 750$ in damages. Roughly 28,000 collisions in our analysis did not involve an officer injury. Therefore, these collisions cost the state of California a minimum of $\$ 210$ million dollars between 2000 and 2009. This estimate is above the cost associated with collisions that injured or killed an officer and may underestimate the actual amount.

The current analysis also revealed some interesting findings related to the characteristics of officer-involved collisions. Counter to what many may have expected (including us), 
younger officers do not appear to be overrepresented in collisions during this time period. This is important because CalPOST (2009) reports and anecdotal evidence relayed to members of the research team by numerous executives and officers in California suggest that officer collisions are a product of young, immature, and inexperienced drivers. On the contrary, however, only about one-quarter of collisions involve an officer driver younger than 30 years of age. It is important to interpret this finding with the appropriate level of caution. The results do not take into consideration the number of officers in California who fall in each of the age categories contained in our analyses. Yet, the prevalence ratios indicate that officers younger than 30 are least likely to be injured or die in collisions. Further research is needed that calculates the rates of officer-involved collisions for particular age groups to determine whether they are disproportionate to the overall number of officers in the state within each category.

Our data also revealed that no female officers were killed in vehicle collisions. This is interesting because nearly 9 percent of collisions involved a female officer driver. It seems unlikely that over a ten-year period this would be a purely coincidental phenomenon. Research that explores this supposed "gender-gap" in officer-involved collision fatalities would be valuable because it could shed light on potential protective factors. Are there personality differences among officers that are involved in fatal collisions compared to those that are not? Are there gender differences in agency assignments that contribute to variation in collision fatality risk?

There are also several important policy implications that can be derived from our analysis. Most notably, the data clearly demonstrate that the operation of motorcycles poses a significant officer safety concern. Nearly four-out-of-ten officers killed in vehicle collisions were operating a motorcycle. What is more, an officer is ten times more likely to die in a vehicle collision if he is driving a motorcycle compared to a car. The same trend is observed with respect to collisions that result in severe injuries to officers. To some, these figures would not appear staggering. After all, motorcycles are clearly more dangerous to operate than cars. This highlights the importance of the following question: Is such an inherent risk to officer safety worth any law enforcement strategic advantage offered by motorcycles? The answer to this question goes beyond the scope of the current study - only law enforcement executives and policy makers can provide this answer. For the sake of argument, however, these data suggest that the fatality and severe injury rates for officerinvolved collisions could each be reduced by 40 percent if motorcycles were not used by California law enforcement agencies. Consistent with earlier estimates, this would also result in nearly $\$ 21$ million saved to local and state jurisdictions (or a reduction of $\$ 135$ million in total financial and loss of quality of life costs).

Finally, our data also reiterate a message that does not appear to resonate well in the law enforcement community - wear your seatbelt! Not surprisingly, officer injury and fatality risk are associated with seatbelt non-use during officer-involved collisions. In fact, nearly 38 percent of all fatalities during the observation period involved an officer that was not wearing a seatbelt. It is not hard to imagine that at least some of these lives could have been saved if a seatbelt was worn. It is vital for future research to uncover the reasons why officers do not wear their seatbelts. Addressing such issues as ergonomic design seems well 
worth the potential advantage of having more officers where their seatbelts. However, it is also important to explore law enforcement cultural factors and individual officer personal reasons for non-use. For example, during informal conversations with many officers throughout the US members of the research team have consistently heard that seatbelts are not worn because the threat of ambush is always present. Wehr et al. (2012) referred to this as the "ninja assassin" rule - although most officers know that it is very unlikely, they must always be prepared for the situation when a bad guy emerges out of nowhere to inflict harm. Having to unclick a seatbelt may cost valuable seconds to an officer attempting to seek cover. Research also suggests that officers who believe their agency treats its employees with respect, dignity, and fairness are more likely to engage in behaviors beneficial to the organization (Wolfe and Piquero, 2011). As such, officer perceptions of their agency's policies and supervision may play a key role in willingness to partake in behaviors such as seatbelt use. Research of this sort goes well beyond an academic exercise. Answers to this question speak directly to officer safety.

In conclusion, it is our hope that the present study strengthens the dialogue among law enforcement executives, policy makers, and street-level officers concerning vehicle collisions and driving safety. Our analysis provides one of the most detailed portraits of officer collisions to date and we hope that others advance on our effort. To do so, criminal justice scholars need to pay closer attention to this issue as an area of research. A majority of the officer collision research is conducted by epidemiologists and traffic researchers. This line of work is small but useful. It is now time that criminologists contribute to the literature. This is particularly important considering the organizational and cultural factors that may drive behaviors associated with collision and injury-severity risk. Lastly, it is important to remember that this set of analyses did not take into consideration the impact of officerinvolved collisions on citizens. Indeed, a significant number of citizens are injured and killed in traffic collisions involving law enforcement officers on an annual basis. Our hope is that the current study will spark future research and serve as a jumping off point for more detailed analyses.

\section{Supplementary Material}

Refer to Web version on PubMed Central for supplementary material.

\section{References}

Alpert GP. Questioning police pursuit in Urban areas. Journal of Police Science and Administration. 1987; 15(4):298-306.

Alpert, GP. Police Pursuit: Policy and Training. National Institute of Justice; Washington, DC: 1997.

Alpert GP, Dunham RG. Policing hot pursuits: the discovery of aleatory elements. The Journal of Criminal Law and Criminology. 1989; 80(2):521-539.

Blincoe, LJ.; Miller, T.; Zaloshnja, E.; Lawrence, BAS. The Economic and Societal Impact of Motor Vehicle Collisions in 2010. National Highway Traffic Safety Administration; Washington, DC: 2014.

Bureau of Justice Assistance (n.d.). Public safety officers' benefits. available at: www.psob.gov/ benefits_by_year.html (accessed April 20, 2010)

POST Driver Training Study: Volume 1. CalPOST; Sacramento, CA: 2009. California Commission of Peace Officer Standards and Training (CalPOST). 
California Highway Patrol. Collision Investigation Manual. California Highway Patrol; Sacramento, CA: 2003.

Crew RE, Hart RA. Assessing the value of police pursuit. Policing. 1999; 22(1):58-73.

Crew RE, Kessler D, Fridell L. Changing hot pursuit police: an empirical assessment of the impact of pursuit behavior. Evaluation Review. 1994; 18(6):678-688.

Dorn L, Brown D. Making sense of invulnerability at work - a qualitative study of police drivers. Safety Science. 2003; 41(10):837-859.

Federal Bureau of Investigations (FBI). Law enforcement officers killed \& assaulted. 2008. available at: www.fbi.gov/ucr/killed/2008/index.html (accessed May 5, 2010)

Gustafson BG, Cappitelli PA. SAFE driving: the role of the chief. The Police Chief. 2010; 77(3):3841.

Noh, EY. Characteristics of Law Enforcement Officers' Fatalities in Motor Vehicle Collisions. National Highway Traffic Safety Administration; Washington, DC: 2011.

Payne DM, Fenske JC. An analysis of the rates of injury and fatal accidents in Michigan state police pursuits: a Michigan emergency response study. American Journal of Police. 1996; 15(4):95-116.

Reaves, BA. Local Police Departments, 2007. US Department of Justice, Office of Justice Programs, Bureau of Justice Statistics; Washington, DC: 2010.

Rix, B.; Walker, D.; Brown, R. A Study of Deaths and Serious Injuries Resulting from Police Vehicle Accidents. Police Research Group Home Office; HMSO, London: 1997.

Stephens, D.; Fielder, ML.; Edwards, SM. OSW Group Annual Summary: Issues and Recommendations Discussed for Improving the Wellbeing of Police Officers. Office of Community Oriented Policing Services; Washington, DC: 2012.

Stephens, D.; Fielder, ML.; Edwards, SM. OSW Group Meeting Summary: Vehicle Operation, Risk Management, and Problem-Based Learning. Office of Community Oriented Policing Services; Washington, DC: Apr 25. 20132012

Tiesman, HM.; Heick, RJ. Law enforcement officer motor vehicle safety: findings from a statewide survey. US Health and Human Services, Centers for Disease Control and Prevention. National Institute for Occupational Safety and Health; Cincinnati, OH: 2014. Publication No. 2015-101

Wehr K, Alpert G, Rojek J. 'The fear of the ninja assassin': understanding the role of agency culture in injurious and fatal on-duty vehicle collisions. Journal of California Law Enforcement. 2012; 46(2): $25-31$.

Whalen, D.; Pepitone, A.; Graver, L.; Busch, JD. Linking Client Records from Substance Abuse, Mental Health, and Medicaid State Agencies. US Department of Health and Human Services; Rockville, MD: 2001.

Wolfe SE, Piquero AR. Organizational justice and police misconduct. Criminal Justice and Behavior. 2011; 38(4):332-353. 


\section{Table I}

Frequency of officer-involved traffic collisions, injuries, and fatalities during the observation period

\begin{tabular}{|c|c|c|c|c|c|}
\hline Year & $\begin{array}{c}\text { Officer-involved } \\
\text { collisions } \\
n\end{array}$ & $\begin{array}{c}\text { Officer } \\
\text { injuries } \\
n\end{array}$ & $\begin{array}{c}\text { Officer } \\
\text { fatalities } \\
n\end{array}$ & $\begin{array}{l}\% \text { of collisions that } \\
\text { resulted in injury }\end{array}$ & $\begin{array}{l}\% \text { of collisions that } \\
\text { resulted in fatality }\end{array}$ \\
\hline 2000 & 3,622 & 825 & 3 & 22.6 & 0.1 \\
\hline 2001 & 3,668 & 829 & 3 & 22.2 & 0.1 \\
\hline 2002 & 3,456 & 788 & 3 & 22.6 & 0.1 \\
\hline 2003 & 3,508 & 822 & 7 & 23.2 & 0.2 \\
\hline 2004 & 3,417 & 779 & 6 & 22.6 & 0.2 \\
\hline 2005 & 3,353 & 732 & 5 & 21.7 & 0.1 \\
\hline 2006 & 3,376 & 694 & 3 & 20.4 & 0.1 \\
\hline 2007 & 3,893 & 756 & 4 & 19.1 & 0.1 \\
\hline 2008 & 3,691 & 716 & 3 & 19.1 & 0.1 \\
\hline 2009 & 3,856 & 743 & 2 & 19.0 & 0.1 \\
\hline Total & 35,840 & 7,684 & 39 & 21.2 & 0.1 \\
\hline
\end{tabular}

Note:

${ }^{a}$ Percentages are calculated by dividing the number of collisions that had at least one officer injury/fatality by the total number of officer-involved collisions in each year 


\section{Table II}

Characteristics of officers involved in traffic collisions throughout the observation period ${ }^{a}$

\begin{tabular}{lrr}
\hline & n & \% \\
\hline Sex & & \\
Male & 33,161 & 91.1 \\
Female & 3,220 & 8.9 \\
Racelethnicity & & \\
White & 23,883 & 65.6 \\
Hispanic & 8,017 & 22.0 \\
Black & 2,250 & 6.2 \\
Asian & 1,525 & 4.2 \\
Other & 639 & 1.8 \\
Missing & 67 & 0.2 \\
Age & & \\
Minimum & 20 & - \\
Maximum & 71 & - \\
Mean & 35.97 & - \\
$20-29$ & 8,897 & 24.5 \\
$30-39$ & 16,278 & 44.7 \\
$40-49$ & 8,611 & 23.7 \\
50 or older & 2,595 & 7.1 \\
\hline
\end{tabular}

Notes: Frequencies sum to greater than the total number of collisions because multiple officers could be involved in a single collision.

${ }^{a}$ Values reported in this table represent descriptive results from the pooled collision data set (i.e. 2000-2009) 
Table III

Officer-involved collisions by agency size during observation period

\begin{tabular}{|c|c|c|c|c|c|}
\hline $\begin{array}{l}\text { Agency } \\
\text { size }^{a}\end{array}$ & $\begin{array}{c}\% \text { of law enforcement } \\
\text { personnel in state } b \\
\%(n)\end{array}$ & $\begin{array}{c}\% \text { of agencies } \\
\text { in the state } \\
\%(n)\end{array}$ & $\begin{array}{c}\% \text { of } \\
\text { collisions } \\
\%(n)\end{array}$ & $\begin{array}{c}\% \text { of collisions } \\
\text { with injuries } \\
\%(n)\end{array}$ & $\begin{array}{c}\% \text { of collisions } \\
\text { with fatality } \\
\%(n)\end{array}$ \\
\hline $0-25$ & $2.7 \%(1,934)$ & $36.5 \%(150)$ & $2.2 \%(780)$ & $1.5 \%(113)$ & $0 \%(0)$ \\
\hline $26-50$ & $4.0 \%(2,812)$ & $19.0 \%(78)$ & $4.3 \%(1,541)$ & $3.3 \%(249)$ & $5.9 \%(2)$ \\
\hline $51-100$ & $8.9 \%(6,272)$ & $20.9 \%(86)$ & $9.9 \%(3,536)$ & $8.4 \%(636)$ & $2.9 \%(1)$ \\
\hline $101-500$ & $20.6 \%(14,501)$ & $18.7 \%(77)$ & $21.7 \%(7,782)$ & $21.6 \%(1,631)$ & $20.6 \%(7)$ \\
\hline $501-999$ & $9.7 \%(6,838)$ & $2.2 \%(9)$ & $8.9 \%(3,175)$ & $8.6 \%(652)$ & $11.8 \%(4)$ \\
\hline $1,000+$ & $54.1 \%(38,074)$ & $2.7 \%(11)$ & $52.5 \%(18,820)$ & $56.6 \%(4,281)$ & $58.8 \%(20)$ \\
\hline Total & 70,431 & 411 & 35,634 & 7,562 & 34 \\
\hline
\end{tabular}

Notes: Values within this table are based on agencies included in the analyses (i.e. values exclude special agencies such as university/college and tribal police).

${ }^{a}$ Agency size categories are constructed based on the ten-year (2000-2009) average number of full-time sworn (FTS) personnel;

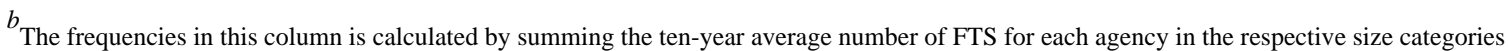
(i.e. they represent the average total number of officers that work within each agency size category over the ten-year observation period);

${ }^{c}$ Values represent the total percentage and frequency of agencies in the state that fall into each agency size category;

${ }^{d}$ Values do not sum to the total number of collisions reported in Table I because there is missing information on agency size for 206 ( 0.6 percent) of agencies 
Table IV

Basic characteristics of officer-involved collisions during observation period

\begin{tabular}{|c|c|c|}
\hline & $n$ & $\%$ \\
\hline \multicolumn{3}{|l|}{ Month } \\
\hline January & 3,050 & 8.5 \\
\hline February & 2,929 & 8.2 \\
\hline March & 2,998 & 8.4 \\
\hline April & 2,869 & 8.0 \\
\hline May & 3,043 & 8.5 \\
\hline June & 2,980 & 8.3 \\
\hline July & 2,695 & 7.5 \\
\hline August & 3,017 & 8.4 \\
\hline September & 3,023 & 8.4 \\
\hline October & 3,175 & 8.9 \\
\hline November & 2,992 & 8.3 \\
\hline December & 3,069 & 8.6 \\
\hline \multicolumn{3}{|l|}{ Day of week } \\
\hline Monday & 4,707 & 13.1 \\
\hline Tuesday & 5,421 & 15.1 \\
\hline Wednesday & 5,558 & 15.5 \\
\hline Thursday & 5,511 & 15.4 \\
\hline Friday & 5,754 & 16.1 \\
\hline Saturday & 4,758 & 13.3 \\
\hline Sunday & 4,131 & 11.5 \\
\hline \multicolumn{3}{|l|}{ Time } \\
\hline 00:01-06:00 & 5,003 & 14.0 \\
\hline 06:01-12:00 & 8,116 & 22.6 \\
\hline 12:01-18:00 & 12,925 & 36.1 \\
\hline $18: 01-24: 00$ & 9,796 & 27.3 \\
\hline
\end{tabular}


Table V

Weather and road conditions during officer-involved traffic collisions during the observation period

\begin{tabular}{lrr}
\hline & $n$ & $\%$ \\
\hline Weather & 28,918 & 80.7 \\
Clear & 5,161 & 14.4 \\
Cloudy & 1,202 & 3.4 \\
Raining & 99 & 0.3 \\
Snowing & 202 & 0.6 \\
Fog & 59 & 0.1 \\
Other & 199 & 0.6 \\
Not stated & & \\
Road surface conditions & 31,992 & 89.3 \\
Dry & 2,928 & 8.2 \\
Wet & 285 & 0.8 \\
Snowy or icy & 285 & 0.8 \\
Slippery (muddy, oily, etc.) & 350 & 1.0 \\
Not stated & & \\
Lighting & 21,163 & 59.0 \\
Daylight & 1,091 & 3.0 \\
Dusk or dawn & 10,368 & 28.9 \\
Dark - street lights & 2,929 & 8.2 \\
Dark - no street lights & 91 & 0.3 \\
Dark - street lights not functioning & 198 & 0.6 \\
Not stated & &
\end{tabular}




\section{Table VI}

Factors surrounding officer-involved traffic collisions during the observation period

\begin{tabular}{|c|c|c|}
\hline & $n$ & $\%$ \\
\hline \multicolumn{3}{|l|}{ Location of collision } \\
\hline Intersection & 8,661 & 24.2 \\
\hline Non-intersection & 26,830 & 74.9 \\
\hline Missing & 349 & 1.0 \\
\hline \multicolumn{3}{|l|}{ Type of collision } \\
\hline Head-on & 1,140 & 3.2 \\
\hline Sideswipe & 6,838 & 19.1 \\
\hline Rear end & 10,879 & 30.4 \\
\hline Broadside & 8,054 & 22.5 \\
\hline Hit object & 5,833 & 16.3 \\
\hline Overturned & 438 & 1.2 \\
\hline Vehicle/pedestrian & 445 & 1.2 \\
\hline Other & 2,030 & 5.7 \\
\hline Not stated & 183 & 0.5 \\
\hline \multicolumn{3}{|l|}{ Number of vehicles involved } \\
\hline Single vehicle & 8,416 & 23.5 \\
\hline Multiple vehicle & 27,424 & 76.5 \\
\hline \multicolumn{3}{|l|}{ Driving under the influence $^{a}$} \\
\hline Had not been drinking & 35,650 & 98.0 \\
\hline Had been drinking, under influence & 29 & 0.1 \\
\hline Had been drinking, not under influence & 33 & 0.1 \\
\hline Had been drinking, impairment unknown & 8 & $<0.1$ \\
\hline Impairment unknown & 69 & 0.2 \\
\hline Not applicable & 243 & 0.7 \\
\hline Not stated & 349 & 1.0 \\
\hline \multicolumn{3}{|l|}{ Officer at-fault ${ }^{a}$} \\
\hline \multicolumn{3}{|l|}{ Single-vehicle collision } \\
\hline Yes & 6,366 & 75.6 \\
\hline No & 2,050 & 24.4 \\
\hline \multicolumn{3}{|l|}{ Multiple-vehicle collision } \\
\hline Yes & 10,402 & 37.2 \\
\hline No & 17,563 & 62.8 \\
\hline
\end{tabular}

Note:

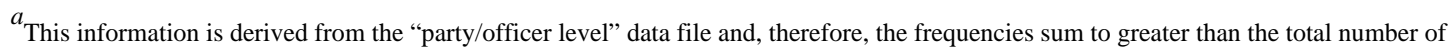
collisions because multiple officer vehicles could be involved in single collision 


\section{Table VII}

Cross-tabulations of officer-involved collision characteristics by injury and fatality outcomes

\begin{tabular}{|c|c|c|c|c|}
\hline & \multicolumn{2}{|c|}{ Officer injured } & \multicolumn{2}{|c|}{ Officer killed } \\
\hline & $\begin{array}{c}\text { Yes } \\
n(\%)\end{array}$ & $\begin{array}{c}\text { No } \\
n(\%)\end{array}$ & $\begin{array}{c}\text { Yes } \\
n(\%)\end{array}$ & $\begin{array}{c}\text { No } \\
n(\%)\end{array}$ \\
\hline \multicolumn{5}{|c|}{ Officer characteristics } \\
\hline \multicolumn{5}{|l|}{ Age } \\
\hline $20-29$ & $1,730(22.5 \%)$ & $7,167(25.0 \%)$ & $4(10.3 \%)$ & $8,893(24.5 \%)$ \\
\hline $30-39$ & $3,485(45.4 \%)$ & $12,793(44.6 \%)$ & $19(48.7 \%)$ & $16,259(44.7 \%)$ \\
\hline $40-49$ & $1,907(24.8 \%)$ & $6,704(23.4 \%)$ & $13(33.3 \%)$ & $8,598(23.7 \%)$ \\
\hline 50 or older & $562(7.3 \%)$ & $2,033(7.1 \%)$ & $3(7.7 \%)$ & $2,592(7.1 \%)$ \\
\hline \multicolumn{5}{|l|}{ Gender } \\
\hline Male & $6,983(90.9 \%)$ & $26,178(91.2 \%)$ & $39(100 \%)$ & $33,122(91.1 \%)$ \\
\hline Female & $701(9.1 \%)$ & $2,519(8.8 \%)$ & $0(0 \%)$ & $3,220(8.9 \%)$ \\
\hline \multicolumn{5}{|c|}{ Officer vehicle type ${ }^{a}$} \\
\hline Car & $6,363(82.8 \%)$ & $27,834(97.0 \%)$ & $24(61.5 \%)$ & $34,173(94.0 \%)$ \\
\hline Motorcycle & $1,321(17.2 \%)$ & $863(3.0 \%)$ & $15(38.5 \%)$ & $2,169(6.0 \%)$ \\
\hline
\end{tabular}

Notes: This analysis is conducted at the "party/officer level." Column percentages are reported.

$a_{6 \text { percent of officers involved in traffic collisions were driving a motorcycle }}$ 


\section{Table VIII}

Cross-tabulations of injury severity by officer vehicle type ${ }^{a}$

\begin{tabular}{lrrr}
\hline & \multicolumn{4}{c}{ Officer vehicle type } & \\
Injury severity & \multicolumn{1}{c}{$\begin{array}{c}\boldsymbol{n}(\boldsymbol{\%}) \\
\text { Motorcycle } \\
\boldsymbol{n}(\boldsymbol{\%})\end{array}$} & $\begin{array}{c}\text { Total } \\
\boldsymbol{n}(\boldsymbol{\%})\end{array}$ \\
\hline Complaint of pain & $5,871(92.0 \%)$ & $509(8.0 \%)$ & $6,380(69.5 \%)$ \\
Other visible injury & $1,726(72.1 \%)$ & $669(27.9 \%)$ & $2,395(26.1 \%)$ \\
Severe injury & $223(60.8 \%)$ & $144(39.2 \%)$ & $367(4.0 \%)$ \\
Fatality & $24(61.5 \%)$ & $15(38.5 \%)$ & $39(0.4 \%)$ \\
Total & $7,844(85.4 \%)$ & $1,337(14.6 \%)$ & 9,181 \\
\hline
\end{tabular}

Notes:

${ }^{a}$ This analysis only examines those officer-involved collisions that had some degree of injury. Furthermore, the analysis is conducted at the "victim/injury-level" such that collisions with multiple officers in a single vehicle are included 


\section{Table IX}

Cross-tabulations of injury severity by officer seatbelt use ${ }^{a}$

\begin{tabular}{|c|c|c|c|c|}
\hline \multirow[b]{2}{*}{ Injury severity } & \multicolumn{3}{|c|}{ Officer seatbelt use $b$} & \multirow[b]{2}{*}{$\begin{array}{l}\text { Total } \\
n(\%)\end{array}$} \\
\hline & $\begin{array}{c}\text { Yes } \\
n(\%)\end{array}$ & $\begin{array}{c}\text { No } \\
n(\%)\end{array}$ & $\begin{array}{c}\text { Not stated } \\
n(\%)\end{array}$ & \\
\hline Complaint of pain & $4,690(79.9 \%)$ & $487(8.3 \%)$ & $694(11.8 \%)$ & $5,871(74.8 \%)$ \\
\hline Other visible injury & $1,056(61.2 \%)$ & $245(14.2 \%)$ & $425(24.6 \%)$ & $1,726(22.0 \%)$ \\
\hline Severe injury & $126(56.5 \%)$ & $41(18.4 \%)$ & $56(25.1 \%)$ & $223(2.8 \%)$ \\
\hline Fatality & $8(33.3 \%)$ & $9(37.5 \%)$ & $7(29.2 \%)$ & $24(0.3 \%)$ \\
\hline Total & $5,880(75.0 \%)$ & $782(10.0 \%)$ & $1,182(15.1 \%)$ & 7,844 \\
\hline
\end{tabular}

Notes:

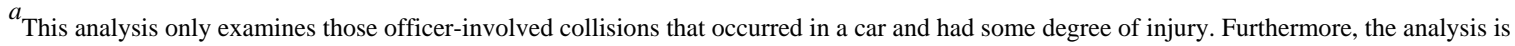
conducted at the "victim/injury-level" such that collisions with multiple officers in a single vehicle are included;

${ }^{b}$ Officers were coded as wearing a seatbelt if they use a lap belt, shoulder harness, or lap and shoulder harness 